\title{
The MESA Study
}

\section{Cameron D. Denson}

\begin{abstract}
This article examines the Mathematics, Engineering, Science Achievement (MESA) program and investigates its impact on underrepresented student populations. MESA was started in California during the 1970s to provide pathways to science, technology, engineering, and mathematics careers for underrepresented students and represents an exemplar model of informal learning environments. Using a mixed-method research design of investigation, this exploratory study looks at the relationship between MESA activities and underrepresented students' self-efficacy, interests, and perceptions related to engineering. Evidences for this study includes data from focus-group interviews conducted and results from quantitative data collected using the Engineering, Self-Efficacy, Interests, and Perceptions Survey (ESIPS) instrument. Results from this study suggest that participation in MESA's activities has a positive influence on underrepresented students' self-efficacy, interests, and perceptions related to engineering.
\end{abstract}

Keywords: Informal learning, underrepresented student populations, mixed methods research

Broadening the participation of underrepresented populations in the science, technology, engineering, and mathematics (STEM) fields is a matter of national security and has become an emphasis for national policy (Strayhorn, 2015). Yet, recent studies have provided evidence that efforts to address these shortages in STEM areas have fallen short. In describing patterns of enrollment in STEM majors, studies revealed that "less than $15 \%$ of undergraduate degrees in engineering, math, and physical science were earned by African American, Latina/o, or Native American . . . students (NSF, 2013)" (MacPhee, Farro, \& Canetto, 2013, p. 348). A recent report revealed a troubling trend for underrepresented student populations entering into STEM majors. Of all the bachelor degrees awarded in 2015, Black students represented only $3 \%$ of this population, Hispanic students a slightly better $8 \%$, and female students only $19 \%$ of all engineering degrees awarded, numbers that are significantly lower than their representation in the general population (National Science Foundation, National Center for Science and Engineering Statistics, 2015). Continuing efforts have tried to address the proportion of participants in engineering who are women and underrepresented minorities, but the demographics of engineering enrollments continue to fall significantly short of the goals of reflecting the demographics of the overall population (Watson \& Froyd, 2007). 
The result is a STEM field that remains overwhelmingly White, male, and ablebodied, leaving the available pool of talented women, minorities, and persons with disabilities significantly underrepresented (May \& Chubin, 2003). To meet this challenge, it is important to identify factors that may help encourage underrepresented student populations to choose careers in STEM fields.

It can be argued that the lack of engineering understanding and a loss of interest in science and mathematics is contributing to the lack of underrepresented students pursuing engineering careers (Jeffers, Safferman, \& Safferman, 2004). To effectively address this problem, educators have sought to create new and innovative pathways for attracting a talent pool to STEM professions that encompasses the diversity evident in the nation's general population (Chubin, May, \& Babco, 2005). The National Academy of Engineering's Committee on K-12 Engineering Education released a report that detailed the status of engineering in $\mathrm{K}-12$ education (Katehi, Pearson, \& Feder, 2009). In this report, the committee stressed the importance of developing curricula with features that appeal to students from underrepresented groups (Katehi et al., 2009). Scientists, engineers, and scholars should not leave the job of recruiting underrepresented populations to STEM careers solely to K-12 teachers of math and science education (Jeffers et al., 2004). Studies show that formal learning environments have traditionally struggled to effectively introduce STEM content and STEM professions to underserved student populations (Denson, Austin, \& Hailey, 2012).

Currently, there is a lack of empirical research on the efficacy of intervention programs to influence underrepresented students (Dyer-Barr, 2014). It is important that comprehensive research studies are employed to help illuminate the practices that are particularly effective in recruiting underrepresented students to STEM careers. One way to address the dearth of literature on best practices for recruiting underrepresented students to STEM careers is to investigate the practices of informal learning environments, particularly those that have been effective in recruiting underrepresented students to STEM careers.

\section{Informal Learning Environments}

Informal learning environments may provide the milieu needed for introducing STEM content to all students, but even more importantly, they may provide a pathway to STEM careers for underrepresented students. It is estimated that students spend $86.7 \%$ of their time outside of a classroom (Gerber, Cavallo, \& Edmund, 2001). This helps illustrate the importance of informal learning environments and the opportunities that they may provide for the teaching and learning of STEM content. Martin (2004) notes that informal learning environments have been an integral part of education for years and will be critical for transforming the teaching of STEM content in the 21 st century. Although the merits of informal learning environments are duly noted, research 
in this area is sparse and undecided on how these experiences benefit students (Gerber et al., 2001). Beyond anecdotal reporting on informal learning environment experiences, there is little research detailing specific activities and their effect on students. This highlights the need to investigate informal learning environments that effectively teach STEM-based concepts to students. Although there are aspects of the program that are conducted during school hours, MESA formally functions as an afterschool program complementing the work of formal STEM curricula. Inferential studies into the ways that informal learning environments are able to impact underrepresented student populations are of particular importance. The results of investigations that explicate how successful informal learning environments impact underrepresented students will provide insight into how the United States can attract diverse populations to STEM fields.

Chubin, May, and Babco (2005) produced a review of engineering-based informal learning environments and concluded that effective engineering-based informal learning environment "must (1) promote awareness of the engineering profession, (2) provide academic enrichment, (3) have trained and competent instructors, and (4) be supported by the educational system of the student participants" (p. 79). Categorically, informal learning environments fall into three settings: (1) "everyday experiences," (2) "designed settings," and (3) "programmed settings" (Kotys-Schwartz, Besterfield-Sacre, \& Shuman, 2011, p. 1). Program settings are characterized by "structures that emulate [or complement] formal school settings - planned curriculum, facilitators or mentors (taking a teaching role), and a group of students who continuously participate in the program [(National Academy of Sciences, 2009)]" (KotysSchwartz et al., 2011, p. 2). The learning environment featured in this study, the Mathematics, Engineering, Science Achievement (MESA) program has been identified as an effective informal learning environment and is categorically identified as a programmed setting (Mathematics, Engineering, Science Achievement [MESA], 2017a). Research has shown that students who participate in the MESA program "outperform California public high school students overall in the following categories: completion of advance mathematics and physics courses, grades and performance on college entrance exams [(Building Science and Engineering Talent, 2004)]" (Kotys-Schwartz et al., 2011, p. 2-3). Due to MESA's success as an informal learning environment and its unmatched ability to recruit and retain underrepresented student populations to STEM careers (MESA, 2017a), researchers for this study were interested in examining the aspects of MESA that appealed to their underrepresented student populations.

This article reports on the results of an investigation into the impact of the MESA program on underrepresented student populations. Using a sequential, exploratory, mixed-method research design, this article adds to the literature focused on underrepresented student populations and informal learning 
environments. This article will first provide the reader with a brief history of the MESA organization followed by the research design framing this study. The article will follow with results from focus-group interviews conducted with MESA participants, which provided eight intriguing themes from the MESA organization and helped informed the design of the Engineering, Self-Efficacy, Interests, and Perceptions Survey (ESIPS) instrument used in this study. Finally, this article will provide results and conclusions from quantitative data collected from over 400 student participants using the ESIPS instrument.

The MESA Organization

The first MESA program was founded in 1970 at Oakland Technical High School in Oakland, California with a membership of 25 students. MESA's goal was "to develop academic and leadership skills, raise educational expectations, and instill confidence in California's students" from groups that were "historically underrepresented in engineering, physical science, or other mathbased fields in order to increase the number of African American, Latino American and American Indian graduates from a four-year university" (MESA, 2017, para. 1). The MESA effort was supported by the California Public School System, the state Community College System, and the California College System. "There may be other established programs, or programs under development, designed to increase Latino academic achievement in mathematics and science, but none has the longevity, organizational structure, network, and academic rigor as does MESA" (Haro, 2004, pp. 218-219). MESA has been able to achieve these goals despite declining federal and state support.

MESA supports educationally disadvantaged students and minority students in middle schools and high schools by providing pathways to help them succeed in science, mathematics and engineering (Kane, Beals, Valeau, \& Johnson, 2004). MESA's goals are to: (1) 'increase the number of engineers, scientists, mathematicians, and related professionals at technical and management levels, and (2) serve as a driving force in encouraging minorities and females in achieving success in these fields" (Maryland MESA, 2012). MESA programs are based on a common co-curricular academic enrichment model that includes "academic planning, community service, family involvement, academic enrichment, hands-on engineering activities, career advising, field trips, competitions and workshops"(MESA USA, 2011). MESA programs represent an innovative way of linking a co-curricular learning environment to mathematics, engineering, and science programs within the formal public-school setting to enhance the STEM education of students.

Over the past 40 years, the California MESA program has become a model for MESA-USA, a partnership that now involves MESA programs from nine states that are joined together to support disadvantaged and underrepresented students to improve their academic achievement in math, science, and engineering. MESA-USA members are active in Arizona, California, Colorado, 
Maryland, New Mexico, Oregon, Utah, Washington, and Pennsylvania. Additional information about the history and status of MESA are available on their website: https://mesa.ucop.edu/about-us/.

MESA "has demonstrated through statistics from their California statewide office that MESA students outperform California public school students overall in the following categories: completion of advanced mathematics and physics courses, grades and performance on college entrance exams [(Building Science and Engineering Talent, 2004)]" (Kotys-Schwartz et al., 2011, pp. 2-3). A review of evaluation reports from after-school science, technology, engineering, and mathematics (STEM) programs, both co-curricular and extracurricular, by the Afterschool Alliance found "that attending high-quality STEM afterschool programs yields STEM-specific benefits that can be organized under three broad categories: improved attitudes toward STEM fields and careers; increased STEM knowledge and skills; and higher likelihood of graduation and pursuing a STEM career" (Afterschool Alliance, 2011, p. 2). Further evidence of the program's impact is that California MESA received the Presidential Award for Excellence in Science, Mathematics, and Engineering Mentoring in 2000, an award administered by the National Science Foundation on behalf of the President.

The success of individual MESA programs has been well documented, including a recent external evaluation conducted by John Hopkins University with the Maryland MESA program (Corcoran, Eisinger, Reilly, \& Ross, 2014). This study looked at MESA's influence on students interest, but it was limited to one state and included just 77 participants (Corcoran et al., 2014), making the results hard to generalize. There is still a need for empirical research that identifies "appropriate content for informal learning models [or environments] or ... assess[es] the degree to which these informal experiences impact students" (Kotys-Schwartz et al., 2011, p. 1), particularly across programs in different states. In response to this need, this article will present qualitative and quantitative data to illustrate the ways in which MESA is able to influence students' self-efficacy, interest, and perceptions of engineering. Furthermore, relationships among students' interest, perceptions, and self-efficacy will be explored, and qualitative data will be presented on the benefits of MESA for underrepresented students. This study was designed to examine students' participation and involvement in five activities that are common among MESA programs: field trips, guest lecturers, design competitions, hands-on activities, and career and academic advisement. 


\section{Methodology}

\section{Research Design}

This study utilized a mixed-method research design. The purpose of this study was to examine the MESA program and understand features of the program that appeal to underrepresented groups. This work complements the work of Tierney and Farmer (2002), by identifying student-oriented activities within the MESA program that have an influence on underrepresented students' engineering self-efficacy, interest in engineering and perceptions of engineering. In addition, focus-group interviews were conducted in an effort to unpack activity variables within the MESA organization and understand the benefits of the program for underrepresented students. The study was conducted in four MESA-USA states: California, Maryland, Washington, and Utah. This study used qualitative and quantitative measures to answer the research questions. The first research question was addressed in the qualitative portion of the study.

1. What are the benefits of participating in MESA for underrepresented student populations?

The second, third, and fourth research questions were addressed in the quantitative portion of the study.

2. What influences do MESA activities have on students' engineering self-efficacy?

3. What influences do MESA activities have on students' interest in engineering?

4. How are the students' perceptions of engineering influenced by their participation in MESA activities?

This study examined student-oriented activities which can be categorized into five distinct groups: (a) field trips, (b) guest lecturers, (c) design competitions, (d) hands-on activities, and (e) student advisement. These five MESA activities represented the independent variables for this study. The dependent variables for this study included students' self-efficacy, interest, and perceptions related to engineering. The study also examined the influence of the MESA program on outcome factors.

Mixed-method research designs are particularly advantageous when seeking to confirm and cross-validate findings within a single study (Creswell, 2009). This study employed an exploratory design of investigation.

Exploratory designs begin with a primary qualitative phase, then the findings are validated or otherwise informed by quantitative results. This approach is usually employed to develop a standardized (quantitative) instrument in a relatively unstudied area. The qualitative phase identifies important factors, while the quantitative phase applies them to a larger 
and/or more diverse sample (Creswell and Piano Clark, 2007). (Borrego, Douglas, \& Amenlink, 2009, p. 59)

In this study, focus-group interviews were used to help identify important features of MESA, which were applied to a larger sample during the quantitative phase. In this study, the qualitative results helped identify features within the MESA program that appealed to underrepresented student populations. In addition, the focus-group results informed instrument development of the ESIPS instrument.

\section{Theoretical Framework}

The theoretical framework that guided this study was social cognitive theory (SCT), which holds that knowledge acquisition is directly related to observing others within their context of social interactions, experiences, and outside media influences (Bandura, 1988). This framework proposes a relationship between outcome expectations and other behavioral factors such as self-efficacy and interest. SCT is based upon the assumption that human ability is a dynamic attribute and that competence in complex tasks requires both welldeveloped skills and a strong sense of efficacy to deploy one's resources effectively. Social cognitive career theory (SCCT) provides a base for exploring the interaction among personal, environmental, and behavioral influences in career development (Lent, Brown, \& Hackett, 1994). This framework is appropriate for this study because of SCT's emphasis on the role that selfefficacy, beliefs, outcome expectations, and goals play in career selection.

Self-efficacy. The first construct to be explored in this study is self-efficacy, as defined by Bandura $(1977,1986)$, which refers to the beliefs about one's ability to execute a given task or behavior in order to attain designated performance. Research has provided evidence that the lack of participation of minorities in STEM careers is due in part to low self-efficacy in science and mathematics. Self-efficacy has been found to be a powerful contributor to the decision to pursue a career in STEM and a major predictor of success in STEM courses (Zeldin, Britner, \& Parajes, 2008). Although studies have examined selfefficacy as it related to STEM fields, few have focused specifically on engineering (Lent et al., 1994). However, there is evidence that self-efficacy regarding scientific-technical tasks is predictive of student interest (Brown, Lent, \& Larkin, 1989) and academic performance (Hackett, Betz, Casas, \& Rocha-Singh, 1992) in STEM fields. Bandura (2006) states that "there is no allpurpose measure of perceived self-efficacy" (p. 307). Sherer et al. (1982) noted that self-efficacy has been primarily thought of as a task-specific belief. Thus, in order to measure engineering self-efficacy, a scale must be created specifically related to the engineering domain. "Self-efficacy scales must be tailored to activity domains and assess the multifaceted ways in which efficacy beliefs operate within the selected activity domain" (Bandura, 2006, p. 310). Although 
some researchers have attempted to create an accurate measure of "general selfefficacy," arguments still persist about the scales validity as a true measure (Chen, Gully, \& Eden, 2001). Sherer et al. (1982) assert that when dealing with specific behaviors, more direct behavioral measures will increase the accuracy of the measurement.

Interest in engineering. The second construct in this study is interest. If one seeks to account for the low numbers of underrepresented students in STEM careers (e.g., Babco, 2001), one need only look at the trend of tracking and the placement of minority students in lower academic tracks which has negatively impacted student interest in the sciences (Museus, Palmer, Davis, \& Maramba, 2011). Multiple studies describe the importance of interest and its relationship to self-efficacy (e.g., Fouad \& Smith, 1996; Hutchinson, Follman, Sumpter, \& Bodner, 2006; Wender, 2004). Bandura (1986) suggested that perceived efficacy in people fostered the growth of intrinsic interest, which would remain consistent as long as those interests engaged their personal feelings and offered satisfaction. The decades old trend of placing minorities in lower academic tracks does not foster intrinsic interest and may contribute to shortages of minority representation in fields such as science and mathematics (Babco, 2001; Boyer, 1983). A lack of interest in learning science and engineering may come about if one does not see science or engineering as a viable career option. Researchers in science education have asserted that one reason students from low-income communities are not interested in science is that there is "a 'disconnect' between school and home/community life" (Basu \& Calabrese Barton, 2007, p. 467). Currently, research offers few solutions on how to sustain these students' interest. However, Basu and Calabrese Barton (2007) found a "strong connection between a sustained interest in science and science learning environments in which students were able to cultivate relationships with people and in ways that reflected their values of relationships and community" (p. 483).

Carlone and Johnson (2007) found that interest in science or science-related fields had less to do with the subject of science than with the effect that their scientific competence would have on the world. The participants in their study were interested in humanitarian work such as health care - efforts that could change the world in a positive way. Interests, along with self-efficacy and outcome expectations, predict intentions, which in turn lead to choice behaviors including those about careers (Lent et al., 1994; Waller, 2006). Waller (2006) also found that African American students' "math self-efficacy and outcome expectations predicted math interest" (p. 543). Brown et al. (1989) showed that even if there is strong interest in a pursuit, if another option is viewed as more attainable that will be the one to which students will strive. In addition to these findings, Fouad and Smith (1996) found that self-efficacy was a large influence on students' interest. Math and science self-efficacy are included among the factors that impact students' interest in engineering. 
Perceptions of engineering. The final construct to be explored is students' perceptions about engineering. A student's perception of an occupation along with their self-efficacy in skills associated with that occupation greatly influence the likelihood that the student will pursue the occupation (Bandura, Barbaranelli, Caprara, \& Pastorelli, 2001). For some individuals, their perceived efficacy rather than their actual achievement is a key determinant of their perceived occupational self-efficacy and preferred choice of work. In a study of African American females, Carlton Parsons (1997) found that 11 of the 20 interviewees imagined a scientist as an unattractive, nerdy, White male. Their image described the male as having a secondary social life with a perfect family. The image that they described did not represent what most African American students see on a daily basis. In fact, negative attitudes toward engineering and "less positive perceptions of the work engineers do" have been reported as key factors in high attrition rates for aspiring engineering students (BesterfieldSacre, Atmn, \& Shuman, 1997; as cited in Hirsch, Gibbons, Kimmel, Rockland, $\&$ Bloom, 2003, p. F2A-7). Changing the public's perception of engineering was a major focus of a study reported in the National Academy of Engineering's (2008) report Changing the Conversation: Messages for Improving Public Understanding of Engineering. These factors highlight the need to address the negative perceptions that underrepresented students have of sciences.

\section{Purpose}

\section{Qualitative Study: Focus-Group Study}

Focus-group interviews were conducted with two goals in mind. First, the researchers were interested in understanding the nuances of the MESA organization by unpacking the activity variables of the informal learning environment. Second, findings from the focus-group interviews would inform instrument development for the quantitative phase of the study. The purpose of the focus-group interviews included determining the benefits of participating in MESA's informal learning environment for underrepresented students.

\section{Methodology}

The research team used a focus-group protocol to guide the interview sessions. "Focus groups are used to gather opinions" (Krueger \& Casey, 2009, p. 2 ). They consist of a series of interviews, conducted with five to 10 participants, wherein the researcher attempts to gain a certain perspective from a particular group (Krueger \& Casey, 2009). Focus-group interviews are well suited for qualitative studies including grounded theory (Webb \& Kevern, 2001). Members of the group are there for member checking, expounding upon participant responses, and adding clarity to group responses.

Focus group interviews typically have five characteristics or features. These characteristics relate to the ingredients of a focus group: (1) people, who (2) 
possess certain characteristics, (3) provide qualitative data (4) in a focused discussion (5) to help understand the topic of interest. (Krueger \& Casey, 2009, p. 6)

In order to ascertain a perspective that was reflective of the MESA program, it was important to establish a "consensus" among group members. For the purpose of this study, researchers felt that focus-group interviews were appropriate. The participants for this study were all members of MESA who provided qualitative data during a focused discussion in an effort to inform the researchers as to the aspects of MESA that were particularly beneficial to their experience.

Focus-group interviews are particularly beneficial when seeking consensus: Interactions among participants enhance data quality because participants provide checks and balances on each other's statements (Patton, 2002). A semistructured interview technique was employed to collect data. During the focusgroup interviews, the interviewer was allowed to digress and probe the students for richer descriptions of activities before returning back to the interview guide to maintain the integrity of the interview process (Krueger \& Casey, 2009).

\section{Participant Selection}

Participants were selected for this study using purposeful sampling. Purposeful sampling is an effective strategy of sampling that allows for the collection of "information-rich" data (Glesne, 2006; Patton, 2002). Advisors for each MESA chapter participating in the study selected participants for the focus groups based on student attendance, achievement, and overall participation in the MESA program. Researchers for this study used a purposeful sampling technique in order to secure participants who could provide insight into the aspects of MESA that were beneficial and understand what students are gaining by their participation. Using a purposeful sample of successful MESA programs, researchers were keen in selecting settings and participants who could help illustrate characteristics of the MESA program that led to student recruitment and retention. It is important to note that this focus-group study was not done in an effort to evaluate the effectiveness of MESA; instead, researchers were investigating the aspects of the program that helped recruit and retain students. Participants were provided with food and refreshments as remuneration for their participation. A total of 28 MESA students from five different schools in the California area participated in the five focus-group interviews. Due to convenience, time constraints, and logistical challenges researchers limited their focus-group populations to schools in California. As an example, over a period of 1 week, researchers rented a car and travelled to six different schools in California to collect the data. The student distribution is as follows: Site 1 provided seven participants, Site 2 provided five participants, Site 3 provided six participants, Site 4 provided five participants, and Site 5 provided five 
participants. In total, there were 19 females and 11 males for a total of 28 student participants. For the duration of this article, participants involved in the qualitative phase will be referred to as focus-group participants in order to distinguish them from the larger student population.

\section{Data Gathering}

Two researchers were responsible for conducting focus-group interviews. For each interview, one researcher served as a facilitator, and the other researcher served as a note taker. Because both researchers were well versed in conducting qualitative research, they alternated roles as facilitator and note taker. The focus-group interviews were audio recorded, and notes were taken to ensure that data could be crosschecked with the audio recordings.

The interviews took approximately 1 hour to complete for each focus group. The facilitators posed two open-ended questions.

1. Can you think of one of the best times you have had in MESA?

2. What do you think you are gaining by participating in MESA? After the first question was asked, the facilitator asked additional probing questions for the purpose of clarification and confirmation. This allowed the participants to answer a multitude of questions with minimal probing from the facilitator. After a number of supplementary questions, the second main question was then posed as a concluding question. Again the process was repeated with the facilitator listening carefully to answers and asking additional or follow-up questions from answers given. The themes formed are the result of four recorded interviews and notes taken from a fifth interview. Technical difficulties prevented transcription of the fifth focus-group recordings.

\section{Analysis}

To build towards a theory of impact and influence relative to MESA activities and underrepresented students, researchers employed a groundedtheory approach to analyze the focus-group results. Grounded theory is an inductive, comparative, iterative method that is used primarily as a method of data analysis. This strategy is useful when striving to render a conceptual understanding from the data (Charmaz, 2001; Dey, 2004). The grounded-theory approach yields themes that are formed from the grouping of codes according to conceptual categories that reflect commonalities among coded data (Glaser \& Strauss, 1967). In this study, researchers examined emergent themes formed from the focus-group participants' responses. This was accomplished by looking at the transcribed recordings and notes that were taken during each interview session. Individual researchers reviewed collected responses and gradually went from coding to categories and eventually theory building, which led to the development of activity components (Harry, Sturges, \& Klingner, 2005). Using the research question as a guiding framework, frequency counts were used to determine themes that were recurrent in order to identify emergent themes. 
Stemler (2001) contends that frequency counts should be used to determine content of particular interest. In qualitative research, "a summative content analysis involves counting and comparisons, usually of keywords or content, followed by the interpretation of the underlying context" (Hsieh \& Shannon, 2005 , p. 1277). Emergent themes were verified only once consensus was reached amongst the researchers regarding these themes.

In providing a rich, thick description of the emergent themes, quotes were used to help paint a picture and to provide "good data" (Morse \& Richards, 2002). Based on the procedures described, readers can have confidence that the conclusions and themes that emerged from the study are in fact a reflection of the participant's responses. To establish consensus, researchers met with the principal investigator for the study to discuss emergent themes from the analysis. Themes included in the results were a result of frequency counts to determine recurrence. After recurrent themes were identified independently by each researcher, researchers provided evidence in the form of student quotes to the Principal Investigator (PI) for this study in order to move into an emergent theme. The PI was not involved in collecting or coding the data and was thus able to provide an unbiased decision about whether evidence was sufficient to justify inclusion as an emergent theme. After themes were agreed upon and justified to a third party, headers were developed to easily identify the characteristics of the prescribed theme.

\section{Results and Discussion}

The results of the grounded-theory approach to analyzing the focus-group responses produced eight disparate themes that spoke to the benefit of the MESA program for underrepresented students: (a) informal mentoring, (b) makes learning fun, (c) time management (d) application of math and science, (e) feelings of accomplishment, (f) builds confidence, (g) camaraderie, and (h) exposure to new opportunities.

Informal mentoring. A surprising theme emerged from the analysis of data from the focus-group interviews. Participants talked more about their roles as mentors in informal mentoring settings, as opposed to the informal mentoring that they received from MESA teachers and advisors. Participants spoke about mentoring not only their fellow underclassmen but also volunteering with local middle and elementary school.

Instead of doing the competition and competing, we get to volunteer-we get to help with the um middle schools and um help them make their projects and give them advice. (Group 1)

We tutor elementary schools too, so there's a lot of elementary schools around. (Group 3) 
Informal mentoring from the MESA advisors and teachers was also mentioned:

This is a club that like wants people, us, all of us, to succeed in life going into college, succeeding in that, all the advisors, all the teachers, just want to see you achieve, to your best quality. So they're going to help you out and to be the best you can be in succeeding. (Group 2)

Makes learning fun. Participants seemed to agree that making learning fun was a key part of MESA's success. They not only spoke of the MESA experiences in reference to learning but also voiced the importance of MESA experiences in changing their perceptions of STEM fields.

It is actually really fun, you don't fall asleep. Um yeah, you don't fall asleep. It's amazing. (Group 1)

If we didn't have the fundamental of math-I mean fun, in between thereit would be really boring. (Group 2)

That's something that MESA shows you at hand. You actually see peopleactually see engineers and they're just out there doing their thing, and they're just having fun and they're enjoying it. (Group 3)

Time management. Organization and time management emerged as a prevalent theme among the focus groups. When speaking about the benefits of MESA, a participant spoke about the impact of the program stating

Like MESA, like kind of helped me like I used to be something like get on time, and something like that do some other stuff with MESA and taught me that I should be doing stuff earlier than doing it at the last second. (Group 4)

The competitions also aided in developing time management skills:

You learn that time is of the essence because we're there working, and then once we get to Saturday academies, or regionals, everything has to be on schedule, or we're running late, you have to turn in project at the certain time, so you're running. (Group 2)

MESA advisors helped participants with the organization necessary for application to college programs:

(MESA helps) when, there's so many deadlines and applications you have to turn in as a senior for college. (Group 1) 
Application of math and science. The focus-group participants expressed an understanding of the importance of having opportunities to apply the math and science learned in formal learning environments. One participant explained the integration of the formal and informal learning environments:

So as I would do MESA, I would get more encouraged and be wait, this is what I was learning in class. So where I would learn something in class, I would use it in MESA, and when I would learn something in MESA I would use it back in my class. You're realizing that this isn't just something you're doing for pointless reasons, but you're doing something with it. (Group 2)

Several participants commented on learning the importance of math and science and also the opportunity for transference of knowledge.

Well the best experience I've had in MESA has been just overall learning the value and importance of math and science. Because we - we put math and science into like-into all these projects we do. (Group 3)

And MESA really brings out-really tells you like - it really gives you an experience of what it's used for. Like here we're doing physics in class, and I'm like what am I going to use this for? You know, how does this apply to me? But then once you do the windmill or something like that .... (Group 1)

Feelings of accomplishment. MESA provided opportunities for participants to achieve outcomes that seemed to be key components in the program. Participants voiced feelings about competing and winning competitions.

One thing you get is just this immense sense of accomplishment, that you did something and it's not [sic] something that you just can't fabricate.

(Group 2)

I get an award, I get this medal on to show that I put that much effort into it. And that's something that MESA does for us. Well to me, it makes me feel accomplished like I actually did something, that I put my work into, and I got something out of it. (Group 3)

We were doing team math, and when we won first place I was, like yes. So it was a good time for me... (Group 4) 
Builds confidence. Participants commented on gaining and building confidence from winning competitions and seeing others like them succeed.

I think I've gained a lot of confidence in myself from MESA, because you do a project, or you give a speech, or you take a math test and you kind of think, I don't know I kind of did okay on that, (Group 4)

Well now that I've done it since 7th grade, it's been easier. Like I'm more calm I know what I'm doing it's just as I go through it I just learned from 7th grade don't be as nervous, just do the best, and just have a little mental power that, you know, I can do it and I can. (Group 2)

Like it make a difference for me because like all my dad, um a lot of his friends from college became engineers, so it's kind of cool because you may of his friends that I've met have been male engineers, and like I go to their companies and it's all like guys working there. So it was kind of cool because like not only was she an engineer, but she was like in charge of many projects. And so like it showed like how it didn't matter so anybody could do-be in charge. (Group 1)

Camaraderie. Although the participants spoke often about participation and placing in various competitions, these activities were often times not what kept them coming back. One of the prevalent themes that we heard was the camaraderie formed by working on projects and visiting different schools while participating in different events. Below are a couple of examples from different groups expressing such thoughts.

Like if you're at prelims you just kind of cheer for your school if they win, but when you go to regionals, if your center wins, then you're cheering for them. But it's not like that serious, like at competitions like you want to win of course, that's what you're doing it for but like everyone is kind of you know relaxed, and everything like everyone talks to everyone. It's not like, you know, you don't talk to them because they're your competitor or whatever. It's kind of like oh, you're here too, how did you do this year? (Group 1)

And when we're doing the trebuchet, we spent countless hours. We would go to our advisors house, stay there from like eight in the morning, and it would be eight at night. And we'd be trying to build it. It would be all the groups and we help each other. (Group 2)

we interact with other schools, and we're - and well, you get to meet new people when you're doing the same project as they are, and they get to give 
you like what Martha said, and everybody else they get to give you hints on what to do on the project, and then besides that, even though you're competing against them, you make new friends that will help you. (Group

2)

The relationships formed among the groups were paramount to why a number of students stay in MESA:

Well, I stayed with people I didn't really know during MESA that year that well, because they were juniors and I was just a sophomore. It was kind of fun I stayed with them, got to know each other better, got closer for this year. So that was really fun to like, you know, all hang out there together. (Group 1)

Exposure to new opportunities. A number of the participants came from backgrounds that do not afford them opportunities to visit college campuses or to work on projects outside of their classrooms. MESA provided a bridge to those participants, which did not go unnoticed or unappreciated.

MESA, it gives you so many opportunities, that a person like me, would never have had. Like my parents were always-like they complain about the hours I put in for like my projects, you know, but they're like oh, you should - you should do that because it gives you the opportunity-like gives you an opportunity to like see things that we'll never- that you'll never get to see with us, you know. Because my parents they're not really, like um - they don't know any English so they can't go anywhere, so they never take me anywhere and they're just like yeah, so you should just like do your best. And join things that would allow you to see others things, you know, give you opportunities. And MESA really does that. (Group 1)

And like one thing is like with engineering and stuff, that it - there's not a club on campus that would allow you to explore that option. There's some for writing and reading, the obvious subjects, but sometimes like engineering is kind of like pushed back because it's math and science, the two most unpopular subjects at a school. And then on top of that, you're asked to do a lot of different projects. And without MESA not a lot of teachers would be willing to have just the fun option of trying this. (Group 2)

Just this last weekend they took some of us juniors to Chico-Chico University and this took us Sunday night and we slept over there at an apartment that these girls share. And so it's not just the fact that you're there, but you get this feeling like you belong. And it's um-you're part of 
the college. And you get to-you get to experience that even before you go to college. And it was really nice we were just - and then we got to visit the dorms we got to visit around school. We saw students, ex-MESA students from this school and they're really happy they say their classes are super hard, but they're loving it. And it's just really nice. And just MESA we're just like-we're really united when it comes to. (Group 3)

\section{Quantitative Study}

The final phase of this mixed-method investigation included the quantitative portion of the data collection, which included over 700 students responding to the survey. The participants came from 22 high schools in the states of California, Maryland, Utah, and Washington. Responses selected for analyses were from individuals who had participated in MESA during the 2012-2013 and 2013-2014 school years. In addition to logistical challenges, communication proved to be a challenge for many states that had agreed to participate in the study. Due to these challenges, data collection extended to over a 2-year period in order to include a diverse set of underrepresented student groups. Below the researchers describe the selection criteria for the participating schools.

For prospective schools to be considered for this study they had to adhere to the following criteria:

1. The high school must have an established MESA program that provided the five student-oriented activities throughout the school year.

2. Students selected will represent underrepresented populations in engineering.

3. Underrepresentation is defined as having a representation in a particular field that is substantially lower than the representation in the general population.

4. Student participants will have at least one academic year of experience in the MESA high school program.

\section{Data Collection}

After school sites indicated interest in participating in the study, a message describing the study and thanking them for their help was sent to the respective site. The message described the purpose of the study and outlined instructions for the administration of the survey. The advisers were asked to have their students complete the survey during a MESA meeting in a room that provided computer and Internet access. A letter of information (LOI) was included with the request that it be sent home to parents or guardians. Some teachers needed hard copies of the LOI, which were sent to them via mail, and others were willing to print copies from an e-mailed PDF file of the LOI. Advisers were informed that if a parent or guardian did not want their child to participate in the study, the parent or guardian should sign and return the form to the adviser. In such a case, the adviser did not allow the student to take the survey. The MESA 
programs at collaborating schools received a stipend for participating in the study. Each adviser was given an individual SurveyMonkey® link to enable participants to complete their individual survey responses and submit their responses electronically to the project office. An exception was made for one school because the adviser requested paper copies to overcome the lack of student access to computers. The responses from that particular school were entered into the database by a project staff member.

Instrument. Data was collected using the ESIPS instrument. The instrument included three subscales for each construct: the self-efficacy subscale contained 11 items, the perceptions subscale contained 12 items, and the interests subscale contained 14 items. There was also an outcomes section that was developed as a result of the qualitative work, which contained 39 items. The ESIPS instrument is a valid and reliable instrument that is the original work of the authors (Denson, Austin, \& Hailey, 2014). Cronbach's alpha was presented as measure of internal consistency or reliability for use with the psychometric measure (Schmitt, 1996). Results of the reliability test provided evidence that the results reported are valid and reliable. Results of the reliability estimates revealed very satisfactory scores for each of the subscales: .93 for the self-efficacy subscale, .85 for the perceptions subscale, .90 for the interest subscale, and .96 for the newly added outcomes subscale. The overall Cronbach Alpha for the survey instrument was 96 .

Data collection for the quantitative phase of this study was conducted at two different intervals with over 700 students responding to the survey. Participants came from 22 high schools in the states of California, Maryland, Utah, and Washington. Responses selected for analyses were from those individuals who had participated in MESA during the 2012-2013 school year. The responses from California, Washington, and most of Maryland schools included in this report were obtained during the 2013-2014 school year. The responses from Utah schools and several Maryland schools were obtained at the end of the 2012-2013 school year. Many individuals who started the survey failed to complete the instrument but scrolled quickly through the items and exited the survey without providing any useful data. The database of returns was scanned manually, and partial results from respondents who had not completed at least one subscale of the survey were not included in the analysis. After this screening, the final sample for the study was composed of 484 students.

\section{Data from Tabulations of Survey Results}

This section begins with demographic data to orient the reader to the characteristics of the sample of respondents. The data provides information about the genders of the respondents and their ethnicities.

Gender. When asked to indicate their gender, 211 respondents indicated that they were male (43.5\%), 239 indicated that they were female $(49.4 \%)$, and $34(7 \%)$ did not respond to the request for gender identification. The distribution 
of the genders varied considerably across the years in high school in the sample. Females outnumbered males in freshman and sophomore years, whereas males outnumbered females in junior and senior years.

Ethnicity. A total of $184(38 \%)$ respondents indicated that they were Hispanic or Latino/Latina, 58 (12\%) indicated that they were White, $26(5.4 \%)$ reported being Black or African American, 117 (24.2\%) indicated that they were Asian, $7(1.4 \%)$ reported that they were American Indian or Alaska Native, 13 $(2.7 \%)$ indicated that they were Native Hawaiian or Pacific Islander, and 79 $(16.3 \%)$ did not respond to the question.

\section{Descriptive Statistics}

The following tables and figures provide descriptive statistics for MESA participants on the following constructs: self-efficacy, perceptions, and interest. The descriptive statistics are presented in order to provide a snapshot of gender, grade, and ethnic differences for each of the prescribed constructs.

Gender differences. Gender differences in the responses to the criterion subscales are consistent across the criterion subscales, with male respondents responding more positively than female respondents on self-efficacy, perception, and interest in engineering. This data is presented in Table 1.

Table 1

Gender Differences

\begin{tabular}{lcc}
\hline & Male & Female \\
\hline Self-efficacy & 3.89 & 3.47 \\
Perception & 4.10 & 3.92 \\
Interest & 3.68 & 3.36 \\
\hline
\end{tabular}

Differences according to ethnicity. There were modest differences in mean responses to each of the criterion subscales among respondents from the respective ethnic groups. Means scores for each ethnic group are provided in Table 2. 
Table 2

Mean Subscale Scores by Ethnicity

\begin{tabular}{lccccccc}
\hline & $\begin{array}{c}\text { Hispanic or } \\
\text { Latino/ } \\
\text { Latina } \\
(n=184)\end{array}$ & $\begin{array}{c}\text { White } \\
(n=58)\end{array}$ & $\begin{array}{c}\text { Black or } \\
\text { African } \\
\text { American } \\
(n=26)\end{array}$ & $\begin{array}{c}\text { Asian } \\
(n=117)\end{array}$ & $\begin{array}{c}\text { American } \\
\text { Indian or } \\
\text { Alaska Native } \\
(n=7)\end{array}$ & $\begin{array}{c}\text { Native } \\
\text { Hawaiian or } \\
\text { Pacific } \\
\text { Islander } \\
(n=13)\end{array}$ & $\begin{array}{c}\text { Undes- } \\
\text { ignated }\end{array}$ \\
\hline Self-efficacy & 3.57 & 3.76 & 3.83 & 3.75 & 3.34 & 3.31 & 3.73 \\
$\begin{array}{l}\text { Perception } \\
\text { Interest }\end{array}$ & 3.97 & 3.98 & 4.05 & 4.06 & 3.95 & 3.86 & 3.93 \\
\hline
\end{tabular}

Mean scores on each of the three criterion subscales increased slightly among respondents in the respective ascending grade levels (see Table 3). It is important to keep in mind that the differences did not necessarily occur within a specific school.

Table 3

Mean Subscale Scores by Grade Level

\begin{tabular}{lcccc}
\hline & Freshman & Sophomore & Junior & Senior \\
\hline Self-efficacy & 3.48 & 3.68 & 3.74 & 3.79 \\
Perception & 3.84 & 3.98 & 4.03 & 4.15 \\
Interest & 3.36 & 3.55 & 3.56 & 3.59 \\
\hline
\end{tabular}

Outcomes assessment. As the work of the project evolved, it became increasingly obvious that a variety of other outcomes (not included in the selfefficacy, perceptions, and interest subscales) resulted from MESA participation. However, the identification of those outcomes was not as clearly specified in the literature, and these outcomes were not as readily measured as the three generally recognized constructs - self-efficacy, perception, and interest. Using analysis from focus-group interviews conducted, a fourth subscale was developed for the assessment of these outcomes, which included specific areas of cognitive development, growth in affective dimensions, career choices, plans for career preparation, and continuing personal development. The revised ESIPS instrument was pilot tested with 224 students deriving from the states of Washington, California, and Utah (Denson et al., 2014). The researchers utilized the techniques of principle component analysis in order to reduce the number of items into a "principle component" that would account for the most variance of the observed variables. The Kaiser-Meyer-Oklin (KMO) measure of sampling adequacy was calculated and found to be acceptable (0.951). Bartlett's test of sphericity was significant $\chi^{2}(741)=6495, p<0.001$. The analysis produced 
four components with eigenvalues greater than one. The Cronbach's Alpha's for the four components are: $\alpha 1=0.928, \alpha 2=0.932, \alpha 3=0.897, \alpha 4=0.894$ (Denson et al., 2014). Analysis of the outcomes subscale provided several insights that offer opportunities for further investigations.

Outcomes of MESA involvement. Responses to items on the outcomes subscale were analyzed by gender and ethnicity. The results of the gender analysis are presented in Table 4. Male respondents had a mean score of 3.89 on the outcomes items, and female respondents had a mean score of 3.78 .

Table 4

Outcome Means by Gender

\begin{tabular}{lccc} 
& Total & Male & Female \\
\hline Outcome means & 3.82 & 3.89 & 3.78 \\
\hline
\end{tabular}

Respondents who identified as Hispanic of Latino/Latina and respondents who identified as Native Hawaiian or other Pacific Islander had the highest mean responses on the outcomes items, 3.88. Black or African American respondents and Asian respondents had mean responses of 3.82, White respondents had mean responses of 3.69, and American Indian or Alaska Native respondents had mean responses of 3.66 on the outcomes items. These results appear in Table 5.

Table 5

Outcomes Means by Ethnicity

\begin{tabular}{lc}
\hline Ethnic Selection & Mean \\
\hline Hispanic or Latino/Latina & 3.88 \\
White & 3.69 \\
Black or African American & 3.82 \\
Asian & 3.82 \\
American Indian or Alaska Native & 3.66 \\
Native Hawaiian or other Pacific Islander & 3.88 \\
\hline
\end{tabular}

\section{Inferential Statistics}

Specific areas of MESA activities. Four categories of MESA activities were studied in more detail: hands-on activities, meeting professionals, student advisement, and field trips. Four facets of each of these activities were explored, each with a statement in this portion of the outcomes instrumentation. Using a 5point Likert type scale, respondents were asked to indicate whether they strongly 
disagree (1 point), disagree (2 points), neither disagree nor agree (3 points), agree (4 points), or strongly agree (5 points) with each statement.

Correlations between participation in MESA activities and means on criteria subscales. One of the most fundamental questions addressed by this study was the influence of involvement in typical MESA activities and subsequent measures of self-efficacy, perceptions of engineering, and interest in engineering. That question is answered most directly by the significant correlations between the means of the hands-on activities, meeting professionals, student advisement, and field trips sections of the survey and the self-efficacy, perception, and interest subscales. Each category of activities was closely correlated with each of the criterion measures. These correlations are reported in Table 6 .

Table 6

Patterns of Responses to Items Assessing Effects of MESA Activities

\begin{tabular}{lcccc}
\hline & $\begin{array}{c}\text { Hands-on } \\
\text { activities }\end{array}$ & $\begin{array}{c}\text { Meeting } \\
\text { professionals }\end{array}$ & $\begin{array}{c}\text { Student } \\
\text { advisement }\end{array}$ & $\begin{array}{c}\text { Field } \\
\text { trips }\end{array}$ \\
\hline Self-efficacy & 0.46 & 0.35 & 0.26 & 0.18 \\
Perceptions & 0.45 & 0.36 & 0.26 & 0.28 \\
Interest & 0.51 & 0.45 & 0.39 & 0.31 \\
\hline
\end{tabular}

Note. All probabilities $<.05^{*}$

The results of the correlation matrix illustrate a positive relationship between MESA's activities and students' self-efficacy, perceptions, and interest of engineering. Closer examination reveals that the most influential activity on the aforementioned constructs is hands-on activities. It should be noted that these comparisons help illustrate the difference in influence for aspects of the MESA program. Results from this analysis do not and should not be seen as predictors of success in other informal learning environments.

Relationship between categories of MESA activities and criterion measures. Competitive events are among the optional opportunities available to MESA participants. The survey probed several aspects of the individuals' involvement in MESA-sponsored competitive events. Respondents who indicated that they participated in competitive events had significantly higher mean scores on the self-efficacy, perception, and interest subscales of the survey. These results are included in Table 7 . 
Table 7

Influence of Participation in MESA Competitions Upon Criterion Measures

\begin{tabular}{|c|c|c|c|c|c|c|}
\hline & \multicolumn{2}{|c|}{$\begin{array}{c}\text { Yes } \\
(n=309)\end{array}$} & \multicolumn{2}{|c|}{$\begin{array}{c}\text { No } \\
(n=161)\end{array}$} & \multirow[b]{2}{*}{$t$} & \multirow[b]{2}{*}{$p$ value } \\
\hline & Mean & $S D$ & Mean & $S D$ & & \\
\hline Self-efficacy & 3.77 & 0.72 & 3.46 & 0.77 & 4.23 & $p<.05^{*}$ \\
\hline Perception & 4.07 & 0.54 & 3.88 & 0.66 & 3.15 & $p<.05^{*}$ \\
\hline Interest & 3.60 & 0.75 & 3.31 & 0.76 & 3.94 & $p<.05^{*}$ \\
\hline
\end{tabular}

Note. Respondents' participation was determined by their answer to the following question: "Did you participate in competitions at the club or class level?"

\section{Conclusion}

It was the researchers' intent to provide some insight into the aspects of informal learning environments that may influence students and the type of events and activities that were particularly attractive to underrepresented student populations. Results of the study include the development of the ESIPS instrument, data from focus-group interviews, and quantitative research results. The mixed-method investigation of the MESA program yielded both quantitative and qualitative research findings and provided empirical evidence of MESA's impact on underrepresented student populations. Results from focusgroup interviews provided insight into the benefits of the MESA program for underrepresented students. These included: (a) informal mentoring, (b) makes learning fun, (c) time management, (d) application of math and science, (e) feelings of accomplishment, (f) builds confidence, (g) camaraderie, and (h) exposure to new opportunities (Denson, Hailey, Stallworth, \& Householder, 2015). The results of the qualitative research informed the development of the ESIPS instrument, which was used for the quantitative research phase (Denson et al., 2014).

The quantitative phase of this mixed-method study included administering the ESIPS instrument to over 700 student respondents. The study was able to use the results of 484 underrepresented students who had participated in MESA. The instrument measured students' self-efficacy, interests, and perceptions related to engineering. Findings from this study appear to corroborate expectations that MESA activities and competitive events make substantial contributions toward the development of MESA participants. Inferential statistics provide evidence that participation in MESA provides positive influences on underrepresented students perceptions, interests, and self-efficacy related to engineering. This study examined the relationship between the aforementioned constructs and MESA's hands-on activities, student advisement, meeting professionals, and field trips. The results revealed that each MESA activity was positively correlated with each of the constructs measured; however, hands-on activities 
seemed to have the strongest impact on students' self-efficacy, interest, and perceptions related to engineering. The study also revealed that students who were active participants in MESA had higher self-efficacy, interest, and perceptions related to engineering.

The MESA respondents in this study appear to follow the general pattern of positive outcomes attributable to participation in structured extracurricular activities reported by Eccles, Barber, Stone, and Hunt (2003) and by Feldman and Matjasko (2005). The MESA experiences of the respondents were perceived as making contributions to their sense of self-efficacy in engineering, their perceptions of engineering, and their interests in engineering. Participation in MESA activities and MESA competitive events had positive outcomes in many dimensions explored in this study. Active involvement in these competitions and organized activities appears to contribute to the development of self-efficacy in engineering, to more accurate perceptions of engineering as a profession, and to enhancing interest in engineering as a field of study and as a career.

The results of this study have several implications for informal learning environments and formal learning environments alike. The results of this study speak to the role of informal learning environments. Operating outside the constraints of standards-based testing and statewide curriculums, the MESA program seems to be effective in impacting students' knowledge, skills, and affective abilities. Although the findings cannot be characterized as surprising, they do appear to corroborate expectations that MESA activities and competitive events make substantial contributions toward the development of MESA participants. Qualitative research results from this study provide empirical evidence as to mechanisms within the MESA organization that appear to make it effective. This is of particular beneficial for formal learning environments that struggle to introduce STEM-based content to underrepresented student populations. In addition, the ESIPS instrument developed for this study is fully adaptable to other engineering-focused informal learning environments and has proven to be a valid and reliable instrument when used in whole or in part. Finally, qualitative results from this study suggest that MESA's activities have an influence on underrepresented students and that student's benefit greatly from their hands-on experiences. Further research should focus on MESA's ability to influence the teaching and learning of STEM content.

\footnotetext{
References

Afterschool Alliance. (2011). STEM learning in afterschool: An analysis of impacts and outcomes. Retrieved from http://www.afterschoolalliance.org/STEM-Afterschool-Outcomes.pdf

Babco, E. L. (2001). Underrepresented minorities in engineering: A progress report. Washington, DC: American Association for the Advancement of Science. Retreived from
} 
http://ehrweb.aaas.org/mge/Reports/Report1/BabcoUnderrepresentedMinoritiesinEngineering.pdf

Bandura, A. (1977). Self-efficacy: Toward a unifying theory of behavioral change. Psychological Review, 84(2), 191-215. doi:10.1037/0033295X.84.2.191

Bandura, A. (1986). Social foundations of thought and action: A social cognitive theory. Englewood Cliffs, NJ: Prentice-Hall.

Bandura, A. (1988). Organizational application of social cognitive theory. Australian Journal of Management, 13(2), 275-302. doi:10.1177/031289628801300210

Bandura, A. (2006). Guide for constructing self-efficacy scales. In F. Parajes \& T. Urdan (Eds.), Self-efficacy beliefs of adolescents (pp. 307-337). Greenwich, CT: Information Age.

Bandura, A., Barbaranelli, C., Caprara, G. V., \& Pastorelli, C. (2001). Selfefficacy beliefs as shapers of children's aspirations and career tajectories. Child development, 72(1), 187-206. doi:10.1111/1467-8624.00273

Basu, S. J., \& Calabrese Barton, A. (2007). Developing a sustained interest in science among urban minority youth. Journal of Research in Science Teaching, 44(3), 466-489. doi:10.1002/tea.20143

Borrego, M., Douglas, E. P., \& Amenlink, C. T. (2009). Quantitative, qualitative, and mixed research methods in engineering education. Journal of Engineering Education, 98(1), 53-66. doi:10.1002/j.21689830.2009.tb01005.x

Boyer, E. L. (1983). High school: A report on secondary education in America. Harper \& Row, Inc., 10 East 53rd Street, New York, NY 10022.

Brown, S. D., Lent, R. W., \& Larkin, K. C. (1989). Self-efficacy as a moderator of scholastic aptitude-Academic performance relationships. Journal of Vocational Behavior, 35(1), 64-75. doi:10.1016/0001-8791(89)90048-1

Carlone, H. B., \& Johnson, A. (2007). Understanding the science experiences of successful women of color: Science identity an an analytic lens. Journal of Research in Science Teaching, 44(8), 1187-1218. doi:10.1002/tea.20237

Carlton Parsons, E. (1997). Black high school females' images of the scientist: Expression of culture. Journal of Research in Science Teaching, 34(7), 745-768. doi:10.1002/(SICI)1098-2736(199709)34:7<745::AIDTEA5>3.0.CO;2-M

Charmaz, K. (2001). Qualitative interviewing and grounded theory analysis. In J. F. Gubrium \& J. A. Holstein (Eds.), Handbook of interview research: Context \& method (pp. 675-694). Thousand Oaks, CA: Sage. doi:10.4135/9781412973588.n39

Chen, G., Gully, S. M., \& Eden, D. (2001). Validation of a new general selfefficacy scale. Organizational Research Methods, 4(1), 62-83. doi: $10.1177 / 109442810141004$ 
Chubin, D. E., May, G. S., \& Babco, E. L. (2005). Diversifying the engineering workforce. Journal of Engineering Education, 94(1), 73-86. doi:10.1002/j.2168-9830.2005.tb00830.x

Corcoran, R. P., Eisinger, J. M., Reilly, J. M., \& Ross, S. M. (2014). An external evaluation of the Maryland Mathematics Engineering and Science Achievement (MESA) program. Baltimore, MD: Center for Research and Reform in Education (CRRE), John Hopkins University. Retrieved from https://secwww.jhuapl.edu/MESA/Content/Docs/618-636.pdf

Creswell, J. W. (2009). Research design: Qualitative, quantitative, and mixed methods approaches (3rd ed.). Thousand Oaks, CA: Sage.

Denson, C., Austin, C. Y., \& Hailey, C. E. (2012, June). Investigating unique aspects of the MESA program for underrepresented students. Paper presented at the 2012 ASEE Annual Conference \& Exposition, San Antonio, TX. Retrieved from https://peer.asee.org/21613

Denson, C. D., Austin, C., \& Hailey, C. (2014, March). Evolution of the ESIPS instrument. Paper presented at the annual conference of the International Technology and Engineering Educators Association, Orlando, FL.

Denson, C. D., Hailey, C., Stallworth, C. A., \& Householder, D. L. (2015). Benefits of informal learning environments: A focused examination of STEM-based learning environments. Journal of STEM Education, 16(1), 11-15. Retrieved from http://www.jstem.org/index.php?journal=JSTEM\&page=article\&op=view\& path $\% 5 \mathrm{~B} \% 5 \mathrm{D}=1893$

Dey, I. (2004). Grounded theory. In C. Seale, G. Gobo, J. F. Gubrium, \& D. Silverman (Eds.), Qualitative research practice (pp. 81-94). Thousand Oaks, CA: Sage. doi:10.4135/9781848608191.d9

Dyer-Barr, R. (2014). Research to practice: Identifying best practices for STEM intervention programs for URMs. Quality Approaches in Higher Education, 5(1), 19-25. Retrieved from http://asq.org/edu/2014/09/research-topractice-identifying-best-practices-for-stem-intervention-programs-forurms.pdf

Eccles, J. S., Barber, B. L., Stone, M., \& Hunt, J. (2003). Extracurricular activities and adolescent development. Journal of Social Issues, 59(4), 865889. doi:10.1046/j.0022-4537.2003.00095.x

Feldman, A. F., \& Matjasko, J. L. (2005). The role of school-based extracurricular activities in adolescent development: A comprehensive review and future directions. Review of Educational Research, 75(2), 159210. doi:10.3102/00346543075002159

Fouad, N. A., \& Smith, P. L. (1996). A test of a social cognitive model for middle school students: Math and science. Journal of Counseling Psychology, 43(3), 338-346. doi:10.1037/0022-0167.43.3.338

Gerber, B. L., Cavallo, A. M. L., \& Marek, E. A. (2001). Relationships among informal learning environments, teaching procedures and scientific 
reasoning ability. International Journal of Science Education, 23(5), 535549. doi:10.1080/09500690116971

Glaser, B. G., \& Strauss, A. L. (1967). The discovery of grounded theory: Strategies for qualitative research. Chicago, IL: Aldine.

Glesne, C. (2006). Becoming qualitative researchers: An introduction (3rd ed.). New York, NY: Pearson.

Hackett, G., Betz, N. E., Casas, J. M., \& Rocha-Singh, I. A. (1992). Gender, ethnicity, and social cognitive factors predicting the academic achievement of students in engineering. Journal of Counseling Psychology, 39(4), 527538. doi:10.1037/0022-0167.39.4.527

Haro, R. (2004). Programs and strategies to increase Latino students' educational attainment. Education and Urban Society, 36(2), 205-222. doi: $10.1177 / 0013124503261331$

Harry, B., Sturges, K. M., \& Klingner, J. K. (2005). Mapping the process: An exemplar of process and challenge in grounded theory analysis. Educational Research, 34(2), 3-13. doi:10.3102/0013189X034002003

Hirsch, L. S., Gibbons, S. J., Kimmel, H., Rockland, R., \& Bloom, J. (2003, November). High school students' attitudes and knowledge about engineering. Paper presented at the 33rd ASEE/IEEE Frontiers in Education Conference, Boulder, CO. doi:10.1109/FIE.2003.1264689

Hsieh, H.-F., \& Shannon, S. E. (2005). Three approaches to qualitative content analysis. Qualitative Health Research, 15(9), 1277-1288. doi:10.1177/1049732305276687

Hutchinson, M. A., Follman, D. K, Sumpter, M., \& Bodner, G. M. (2006). Factors influencing the self-efficacy beliefs of first-year engineering students. Journal of Engineering Education, 95(1), 39-47. doi:10.1002/j.2168-9830.2006.tb00876.x

Jeffers, A. T., Safferman, A. G., \& Safferman, S. I. (2004). Understanding K-12 engineering outreach programs. Journal of Professional Issues in Engineering Education and Practice, 130(2), 95-108. doi:10.1061/(ASCE)1052-3928(2004)130:2(95)

Kane, M. A., Beals, C., Valeau, E. J., \& Johnson, M. J. (2004). Fostering success among traditionally underrepresented student groups: Hartnell College's approach to implementation of the Math, Engineering, and Science Achievement (Mesa) Program. Community College Journal of Research and Practice, 28(1), 17-26. doi:10.1080/10668920490251944

Katehi, L., Pearson, G., \& Feder, M. (Eds.). (2009). Engineering in K-12 education: Understanding the status and improving the prospects. Washington, DC: National Academies Press. doi:10.17226/12635

Kotys-Schwartz, D., Besterfield-Sacre, M., \& Shuman, L. (2011, October). Informal learning in engineering education: Where we are-Where we need to go. Paper presented at the 41st ASEE/IEEE Frontiers in Education Conference, Rapid City, SD. doi:10.1109/FIE.2011.6142836 
Krueger, R. A., \& Casey, M. A. (2009). Focus groups: A practical guide for applied research (4th ed.). Thousand Oaks, CA: Sage.

Lent, R. W., Brown, S. D., \& Hackett, G. (1994). Toward a unifying social cognitive theory of career and academic interest, choice, and performance. Journal of Vocational Behavior, 45(1), 79-122. doi:10.1006/jvbe.1994.1027

MacPhee, D., Farro, S., \& Canetto, S. S. (2013). Academic self-efficacy and performance of underrepresented STEM majors: Gender, ethnic, and social class patterns. Analyses of Social Issues and Public Policy, 13(1), 347-369. doi:10.1111/asap.12033

Martin, L. M. W. (2004). An emerging research framework for studying informal learning and schools. Science Education, 88(S1), S71-S82. doi: $10.1002 /$ sce. 20020

May, G. S., \& Chubin, D. E. (2003). A retrospective on undergraduate engineering success for underrepresented minority students. Journal of Engineering Education, 92(1), 27-39. doi:10.1002/j.21689830.2003.tb00735.x

Maryland MESA (Mathematics, Engineering, Science Achievement). (2012). Engineering competitions for K-12 students. Retrieved from http://competitions.umd.edu/content/maryland-mesa-mathematicsengineering-science-achievement

Mathematics, Engineering, Science Achievement. (2017). Milestones in MESA history: 1970. Retrieved from https://mesa.ucop.edu/about-us/mesa-history/

Mathematics, Engineering, Science Achievement. (2017). About us. Retrieved from https://mesa.ucop.edu/about-us/

MESA USA. (2011). Mathematics, Engineering, Science Achievement. Retrieved from https://archive.is/0zxA

Morse, J. M., \& Richards, L. (2002). Readme first for a user's guide to qualitative methods. Thousand Oaks, CA: Sage.

Museus, S.D., Palmer, R.T., Davis, R.J., \& Maramba, D.C. (2011). Racial and ethnic minority students' success in STEM education [Special issu]. Ashe Higher Education Report, 36 (6). doi: 10.1002/aehe.3606

National Academy of Engineering. (2008). Changing the conversation: Messages for improving public understanding of engineering. Washington, DC: National Academies Press. doi:10.17226/12187

National Science Foundation, National Center for Science and Engineering Statistics. (2015). Women, Minorities, and Persons with Disabilities in Science and Engineering. Arlington, VA. Retrieved from https://www.nsf.gov/statistics/wmpd/archives/wmpd-2015.zip

Patton, M. Q. (2002). Qualitative research and evaluation methods (3rd ed.). Thousand Oaks, CA: Sage.

Schmitt, N. (1996). Uses and abuses of coefficient alpha. Pyschological Assessment, 8(4), 350-353. doi:10.1037/1040-3590.8.4.350 
Sherer, M., Maddux, J. E., Mercandante, B., Prentice-Dunn, S., Jacobs, B., \& Rogers, R. W. (1982). The self-efficacy scale: Construction and validation. Pyschological Reports, 51(2), 663-671. doi:10.2466/pr0.1982.51.2.663

Stemler, S. (2001). An overview of content analysis. Practical Assessment, Research \& Evaluation, 7. Retrieved from http://pareonline.net/getvn.asp?v=7\&n=17

Strayhorn, T. L. (2015). Factors influencing Black males' preparation for college and success in STEM majors: A mixed methods study. The Western Journal of Black Studies, 39(1), 45-63.

Tierney, P., \& Farmer, S., M. (2002). Creative self-efficacy: Its potential antecedents and relationship to creative performance. Academy of Management Journal, 45(6), 1137-1148. doi:10.2307/3069429

Waller, B. (2006). Math interest and choice intentions of non-traditional African-American college students. Journal of Vocational Behavior, 68(3), 538-547. doi:10.1016/j.jvb.2005.12.002

Watson, K., \& Froyd, J. (2007). Diversifying the U.S. engineering workforce: A new model. Journal of Engineering Education, 96(1), 19-32. doi:10.1002/j.2168-9830.2007.tb00912.x

Webb, C., \& Kevern, J. (2001). Focus groups as a research method: A critique of some aspects of their use in nursing research. Journal of Advanced Nursing, 33(6), 798-805. doi:10.1046/j.1365-2648.2001.01720.x

Wender, I. (2004). Relation of technology, science, self-concept, interest, and gender. Journal of Technology Studies, 30(3), 43-51. doi:10.21061/jots.v30i3.a.7

Zeldin, A. L., Britner, S. L., \& Parajes, F. (2008). A comparative study of the self-efficacy beliefs of successfull men and women in mathematics, science, and technology careers. Journal of Research in Science Teaching, 45(9), 1036-1058. doi:10.1002/tea.20195

\section{About the Author}

Cameron D. Denson (cddenson@ncsu.edu) is Assistant Professor of Technology, Engineering, and Design Education at North Carolina State University. 